\title{
Dermatoses in Himalayas: Pattern of Skin Diseases in Himalayan Region of Nepal
}

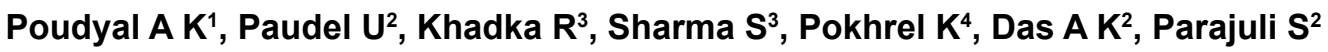 \\ ${ }^{1}$ Department of Community Medicine and Public Health, Maharajgunj Medical Campus, Institute of Medicine, Tribhuvan \\ University, Kathmandu, Nepal, ${ }^{2}$ Department of Dermatology, Maharajgunj Medical Campus, Institute of Medicine, \\ Tribhuvan University Teaching Hospital, Institute of Medicine, Kathmandu, Nepal, ${ }^{3}$ District Hospital, Simikot, Humla, \\ ${ }^{4}$ Department of Dermatology, Nepalgunj Medical College, Nepalgunj, Nepal
}

Financial support: Society of Dermatologists, Venereologists \& Leprologists of Nepal provided the cost of medical camp.

\begin{abstract}
Background: Skin diseases are the major cause of out-patient visit in Nepal. Department of Health Services, Nepal ranks skin diseases as fourth common cause of out-patient visit throughout the country. The objective of the study was to determine the pattern of different skin diseases in Himalayan region of Nepal.

Material and methods: A cross sectional descriptive study design was conducted in a health camp setting in which 148 community people visited the camp with dermatological diseases. Information about socio-demographic and dermatological diseases were collected with a structured performa.

Results: The most common primary diagnosis was pigmentary anomaly ( $20.3 \%)$ followed by Eczemas (18.9\%), Superficial mycoses $(10.8 \%)$, and acne $(10.1 \%)$. In all skin diseases male were more affected as compared to female.

Conclusions: The dermatoses of Himalayan region are pigmentary anomalies being most common, followed by eczemas, superficial mycoses, acne, photodermatoses, scabies, urticaria, benign tumours and pyodermas.

Key words: Skin diseases, Himalayan, Nepal
\end{abstract}

\section{Introduction}

kin diseases are the major cause of out-patient

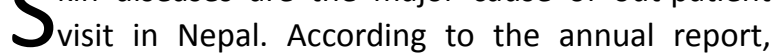
Department of Health Services 2010/2011, skin diseases was $4^{\text {th }}$ common cause of out-patient visit throughout the country. ${ }^{1}$ There are only couple of studies which show the prevalence of the skin diseases in Nepal. All these studies vary in the methodology and outcome with resultant variation in prevalence of skin diseases. Most of the studies are hospital based and few of them are community based ${ }^{2-5}$. The study on pattern of skin diseases in Himalayan district of Nepal has not been documented. This study is an attempt

\section{Address for correspondence}

Amod Kumar Poudyal

Associate Professor

Department of Community Medicine and Public Health, Maharajgunj Medical Campus, Institute of Medicine, Tribhuvan University

Office contact no: 01-4424860

Mobile no: 9851011037

E-mail:amod103@gmail.com to define the pattern of skin diseases in one of the Himalayan district of Nepal, Humla district.

Humla district, one of Nepal's highest and most inaccessible district, is situated in far northwest of Nepal, bordering the Tibet, China. The common means of transportation are mules which bring required products from the Tibetan border to Simikot. The closest road-head to Humla is nine days walk to the south; and from Tibet six days walk away to the northeast. Humla has a population of about $50,858 .{ }^{6}$ Its elevation ranges from 1,524 to 7,337 meters above the sea level. We chose Simikot, headquarters of Humla district arbitrarily to see the pattern of skin diseases in Himalayan region of Nepal. The objective of the study was to determine the pattern of different skin diseases in Himalayan region of Nepal. This type of study has never been conducted in Humla district before.

\section{Material and methods}

A cross sectional descriptive health camp based study design was adopted. The camp was organized on 
the last week of October 2013 by Kathmandu based organization, Society of Dermatologists, Venereologists \& Leprologists of Nepal (SODVELON) with a team comprising of two Dermatologists, and two medical officers at Simikot district hospital. A week ahead of the health camp, information about the skin health camp was aired from Simikot based FM radio station for seven days. In the information, all the person who think of having skin diseases were asked to visit the one-day skin health camp for free of cost examination, treatment and counseling. The camp was open from $8.30 \mathrm{am}$ to $4.30 \mathrm{pm}$. Informed consent was taken before registering the patients. All the patients were examined once for the skin disease by registered Dermatologist. In addition to the primary complaint, the patient were examined in to for any other skin diseases they are living with. When a diagnosis was in doubt, opinion of a second Dermatologist was taken. The skin diseases were divided into a number of categories as defined by International foundation of Dermatology namely scabies, superficial mycoses, pyoderma, pediculosis, eczema, HIV related Dermatoses, pigmentary anomalies, and acne. ${ }^{7}$ Urticarias, benign tumours, and appendageal tumours were also added in addition to these diseases. The demographic details and the diagnosis of the disease were recorded in preformed proforma.

Individuals who were identified as having individual skin disease were given appropriate treatment and advice free of cost. Only the cases requiring histopathological examination were referred to tertiary care centres (TU Teaching Hospital, Kathmandu or Nepalgunj Medical College, Nepalgunj).

\section{Results}

A total of 148 patients were examined for skin diseases out of which 102 (68.9\%) were males and 46 (31.1\%) were females. The mean age was 25.3 years \pm 11.95 SD. The age range of those examined was 3 months to 60 years.

More than half (55.4\%) of the total patients were from Brahmin/Chhetri/ Thakuri ethnic group. Most of the patients who came for health check up were office worker (34.5\%), followed by students (33.1\%), farmers and housewives (21.6\%). The other group consisted preschool kids, Monks and business people (table 1).

Most of the patients were Hindus (77.7\%), followed by Buddhists (20.9\%) and Christian (1.2\%).

Of these patients (62.0\%) had SLC and above education while $12.0 \%$ were uneducated.
Almost all the patients were from Humla district $(88.5 \%)$ whereas only $11.5 \%$ were from other districts.

The median time travelled to camp by walking was 3 hours (Q1= 30 minutes, Q3=24 hours). Forty-four (30.0\%) of total camp visitors, walked more than 24 hours to reach the camp. One of the patients had traveled 96 hours to reach the camp.

A wide range of Dermatoses was identified. The dermatoses has been shown in table 2

The most common primary diagnosis was pigmentary anomaly $(20.3 \%)$ which was much higher on male (76.7\%) as compared to female (23.3) followed by Eczemas (18.9\%), Superficial mycoses (10.8\%), acne (10.1\%), Photodermatoses (8.1\%), Scabies (6.8\%), Urticarias (6.1\%), Benign tumours (4.7\%), pyodermas(1.4\%) and others( $12.8 \%)$.

\section{Discussion}

In recent few years, the epidemiological studies on skin diseases in Nepal has increased. However, most of these studies are confined to Terai and Hilly regions of Nepal. In one of the studies conducted by Shrestha $R$ et $\mathrm{al}^{8}$ in rural village development community of hilly region of Nepal, the camp prevalence of skin diseases was $83 \%$ with eczema (36.4\%), followed by infections (28.4\%), acne (22\%), Pigment disorders (34\%), and Urticaria (12.3\%). In another similar study in Terai region by Walker $\mathrm{SL}$ et $\mathrm{al}^{3}$, the point prevalence of skin disease in camp was $62.2 \%$ with dermatophyte infections (11.4\%) being the commonest followed by P. versicolor (8.9\%), Acne( 7.7\%), Melasma (6.8\%), eczemas $5.6 \%$ ) and P. alba (5.2\%). In another study by Shrestha DP et al $^{2}$, in which a house- to-house survey of skin disease was done, overall prevalence of Skin disease was shown to be $20.1 \%$, with eczemas (12.2\%) being the most common dermatoses followed by pigment disorder (4.1\%), acne( $2.7 \%)$, urticaria(2.4\%), and moles and lumps(1.6\%). The same study had concluded that skin disease has large impact on quality of life of people of Nepal. The two studies from hilly region of Nepal shows eczema as one of the most common dermatoses in this region while infections were the most common predominating in Terai Region.

In our Study, the dermatoses of Himalayan region of Nepal were most commonly seen in males than females, with the disease seen across all age group, the most common being the adult group (21-30 years). The reason could be because the males might have more health seeking behavior compared to females in this region. Office worker were most common group 
to visit the camp which could be because of awareness of disease in this group. Hindus were more in number to seek the health related service in our camp, and it could be because of awareness of health seeking behavior in this group. The educated group of people were most common to seek the service probably because of increased perceptibility of disease in this group.
In this study it was seen that the patient had traveled to camp by walking up to 96 hour to reach to our camp. This reflects the difficulty of receiving health service because of complex geography of this region. Moreover, it could justify introduction of newer technology such as telemedicine in this region especially in Dermatological services.

Table 1: Socio-demographic characteristics of the patients

\begin{tabular}{|c|c|c|c|c|c|c|}
\hline & \multicolumn{2}{|c|}{ Male } & \multicolumn{2}{|c|}{ Female } & \multicolumn{2}{|c|}{ Total } \\
\hline & $\mathrm{n}$ & $\%$ & $\mathbf{n}$ & $\%$ & $\mathbf{n}$ & $\%$ \\
\hline \multicolumn{7}{|l|}{ Age } \\
\hline $0-10$ & 7 & 63.6 & 4 & 36.4 & 11 & 7.4 \\
\hline $11-20$ & 33 & 75.0 & 11 & 25.0 & 44 & 29.7 \\
\hline $21-30$ & 43 & 66.2 & 22 & 33.8 & 65 & 43.9 \\
\hline $31-40$ & 7 & 63.6 & 4 & 36.4 & 11 & 7.4 \\
\hline $41-50$ & 6 & 60.0 & 4 & 40.0 & 10 & 6.8 \\
\hline $51-60$ & 6 & 85.7 & 1 & 14.3 & 7 & 7.4 \\
\hline \multicolumn{7}{|l|}{ Ethnicity } \\
\hline Bramin/Chhetri/Thakuri & 54 & 65.9 & 28 & 34.1 & 82 & 55.4 \\
\hline Janajati & 39 & 70.9 & 16 & 29.1 & 55 & 37.2 \\
\hline Dalit & 9 & 81.8 & 9 & 18.2 & 11 & 7.4 \\
\hline \multicolumn{7}{|l|}{ Education } \\
\hline Illiterate & 8 & 47.1 & 9 & 52.9 & 17 & 12.0 \\
\hline Primary level & 11 & 57.9 & 8 & 42.1 & 19 & 13.4 \\
\hline Secondary level & 13 & 72.2 & 5 & 27.8 & 18 & 12.6 \\
\hline SLC and above & 66 & 75.0 & 22 & 25.0 & 88 & 62.0 \\
\hline \multicolumn{7}{|l|}{ Occupation } \\
\hline Office worker & 42 & 82.4 & 9 & 17.6 & 51 & 34.5 \\
\hline Students & 33 & 67.3 & 16 & 32.7 & 49 & 33.1 \\
\hline Farmer/house wives & 17 & 53.1 & 15 & 46.9 & 32 & 21.6 \\
\hline Others & 10 & 62.5 & 6 & 37.5 & 16 & 10.8 \\
\hline Total & 102 & 68.9 & 46 & 31.1 & 148 & 100 \\
\hline
\end{tabular}

Table 2: Patterns of Dermatoses

\begin{tabular}{|l|c|c|c|c|c|c|}
\hline \multirow{2}{*}{\multicolumn{1}{|c|}{ Primary diagnosis }} & \multicolumn{2}{c|}{ Male } & \multicolumn{2}{c|}{ Female } & \multicolumn{2}{c|}{ Total } \\
\cline { 2 - 7 } & $\mathbf{n}$ & $\mathbf{9}$ & $\mathbf{n}$ & $\mathbf{\%}$ & $\mathbf{n}$ & $\mathbf{2}$ \\
\hline Pigmentary anomalies & 23 & 76.7 & 7 & 23.3 & 30 & 20.3 \\
\hline Eczema & 18 & 64.3 & 10 & 35.7 & 28 & 18.9 \\
\hline Superficial mycoses & 12 & 75.0 & 4 & 25.0 & 16 & 10.8 \\
\hline Acne & 9 & 60.0 & 6 & 40.0 & 15 & 10.1 \\
\hline Photodermatoses & 6 & 50.0 & 6 & 50.0 & 12 & 8.1 \\
\hline Scabies & 5 & 50.0 & 5 & 50.0 & 10 & 6.8 \\
\hline Urticaria & 7 & 77.8 & 2 & 22.2 & 9 & 6.1 \\
\hline Benign tumours & 7 & 100.0 & - & - & 7 & 4.7 \\
\hline Pyoderma & 2 & 100.0 & - & - & 2 & 1.4 \\
\hline Others & 13 & 68.4 & 6 & 31.6 & 19 & 12.8 \\
\hline Total & $\mathbf{1 0 2}$ & $\mathbf{6 8 . 9}$ & $\mathbf{4 6}$ & $\mathbf{3 1 . 1}$ & $\mathbf{1 4 8}$ & $\mathbf{1 0 0}$ \\
\hline
\end{tabular}


Pigmentary anomaly was the most common dermatoses seen in our study in contrast to eczemas and fungal infections seen in hilly and Terai region respectively. The high intensity of Ultraviolet rays in this region could explain this pattern. However, there were no cases of cutaneous malignancies despite the assumed high Ultraviolet rays exposure, which could be explained by protective skin type in our population or else it could be question of next research.

\section{Conclusion}

The dermatoses of Himalayan region are slightly different from the dermatoses of hilly and Terai region of Nepal with pigmentary anomalies being most common, followed by eczemas, superficial mycoses, acne, photodermatoses, scabies, urticaria, benign tumours and pyodermas. These dermatoses pattern reflect the basic data of one of the Himalayan region of Nepal.

Acknowledgements: The authors would like to extend sincere thanks to all the participants of the camp. We also would like to express our special thanks to the district hospital Simikot, Humla and its staffs for their valuable support to carry out the dermatological health camp.

\section{References}

1. Annual report, Department of Health Sciences, Government of Nepal, Ministry of Health and Population, Department of Health services, Kathmandu, 2010/2011

2. Shrestha DP, Gurung D, Rosdahl I. Prevalence of skin diseases and impact on quality of life in hilly region of Nepal. JIOM 2012; 34: 44-9.

3. Walker SL, Shah M, Hubbard VG, Pradhan $\mathrm{HM}$, Ghimire M. Skin disease is common in Nepal: result of a point prevalence study. B J Dermatol 2006; 158: 334-8.

4. Karn D, Khatri R, Timalsina M. Prevalence of skin diseases in Kavre district, Nepal. NJDVL 2010; 9: 7-9.

5. Jha SM, Rajbhandari SL, Shakya N, Pokharel A, Jha B. Pattern of Dermatological diseases in the patients of Army Hospital, Kathmandu. Medical journal of Shree Birendra Hospital 2010; 9: 146. http://dx.doi.org/10.3126/mjsbh.v9i1.3484

6. National Planning Commission, Central Bureau of Statistics, National Population and Housing Census 2011 vol1, Kathmandu, Nepal 2012.

7. Hay R, Bendeck SE, Chen S, Estrada R, Haddix A, McLeod T et al. Skin diseases. In: Jamison DT, Breman JG, Measham AR, Alleyne G, Claeson $M$, Evan DB, editors. Disease control priorities in Developing Countries. $2^{\text {nd }}$ ed. New York: World Bank and Oxford University Press; 2006: 707-21.

8. Shrestha R, Lama L, Gurung D, Shrestha DP, Rosdahl I. Pattern of skin diseases in a rural village development community of Nepal. NJDVL 2014; 12: 41-4. http://dx.doi. org/10.3126/njdvl.v12i1.10595 